\title{
A Compact Dual Band Printed Monopole Antenna
}

\author{
Sudipta Das ${ }^{1 *}$, Partha Pratim Sarkar ${ }^{2}$ and Santosh Kumar Chowdhury ${ }^{3}$ \\ $1^{*}$ Department of ECE, IMPS CET, Malda, W.B, India, \\ ${ }^{2}$ Department of Engineering and Technological Studies, University of Kalyani, \\ Nadia, W.B, India \\ ${ }^{3}$ Ex-Professor, Department of Electronics and Tele-Communication Engineering, \\ Jadavpur University, Kolkata, W.B, India \\ I*Sudipta.das1985@gmail.com
}

\begin{abstract}
In this paper, a microstrip line fed dual band printed monopole antenna for applications in WLAN, HiPERLAN, HisWaNa and WiMAX is presented. The presented antenna, occupying a compact size of $25 \times 18 \mathrm{~mm}^{2}$ embodies a simple microstrip line fed rectangular patch and a partial rectangular ground plane defected with small $U$ shaped slot. The small U shaped slot having an area of only $3 \times 4 \mathrm{~mm}^{2}$ is introduced in the ground plane to obtain dual frequency operation with broad operating bandwidth. The antenna is fabricated on FR-4 substrate of thickness $1.585 \mathrm{~mm}$ and relative permittivity 4.4. The measured result shows dual band operation with wide $10 \mathrm{~dB}$ impedance bandwidths of $680 \mathrm{MHz}(2.92-3.6 \mathrm{GHz})$ and $2300 \mathrm{MHz}(4.12-6.42 \mathrm{GHz})$ which covers the bandwidth requirements of 5.2/5.8 GHz WLAN, $5 \mathrm{GHz}$ HiPERLAN, 3.5/5.5 GHz WiMAX and 5.2 $\mathrm{GHz}$ HisWaNa application bands.
\end{abstract}

Keywords: Compact, Dual band, Printed monopole antenna, Wireless Communication

\section{Introduction}

The wireless communication systems have been developed widely and rapidly during the last decade. Presently, certain specific bands of frequencies are allotted for different wireless communication systems. A single antenna with dual frequency or multi frequency capabilities to satisfy the required operating frequency bands is more desirable due to limited equipment space. In recent years, printed monopole antenna fed by coplanar waveguide (CPW) or microstrip line has become very popular in wireless communication industry, owing to its many attractive features, such as smaller size, ease of fabrication, low cost, ease of integrating with active devices and nearly omni-directional radiation characteristics, and so on. The modified planar monopole configuration is often adopted to realize dual-band operation, such as a meander T-shaped monopole [1], slot monopole [2], cross-slot monopole [3], monopole antenna using a simple inverted U shaped driven element [4], folded strip monopole antenna with a protruding stub in the ground plane [5], printed antenna with h-shaped stub resonator and T-shaped monopole radiator [6], wide open U slot monopole antenna with a pair of symmetrical L strips [7] and a monopole antenna using U shaped ground plane [8]. But the proposed monopole antennas [1-8] have either complex structure or large overall size for the limited space of a portable device. To further reduce the antenna size, the coplanar waveguide fed slot antennas [9-10] are employed to meet the requirements of multi-band operation. Researchers have investigated on asymmetric coplanar strip fed structures but they suffer from poor radiation pattern due to the asymmetry in their structures [11-12]. 
In this article, a compact microstrip-fed planar monopole antenna using a small $\mathrm{U}$ shaped slot loaded partial ground plane has been presented for wireless communication applications. The proposed printed monopole antenna provides dual broad frequency bands with much smaller antenna size and less complex structure compared to the dual band monopole antennas proposed in Refs. [1-8]. In this design, it is more attractive that the proposed monopole antenna has one sharp stop band compared with the antennas presented in Refs. [9-10] and this will surely improve the performance of applicable dual band systems. The proposed monopole antenna also indicates better stable radiation patterns characteristics compared to Refs. [11-12]. The novelty of the proposed work is dual frequency operation with broad impedance bandwidth by introducing a single small $\mathrm{U}$ shaped slot into the ground plane and without any modification in the radiating patch. The proposed antenna has achieved broad impedance bandwidth without using thick foam or air substrates. The structure of the antenna is very simple and easy to fabricate. The proposed antenna provides good radiation characteristics in much smaller size. Moreover, the same antenna covers the bandwidth requirements of a number of modern wireless communication systems such as WLAN $(5.15-5.35 \mathrm{GHz}, 5.725-5.825 \mathrm{GHz})$, WiMAX (3.3-3.6 GHz, 5.25-5.85 GHz), HiPERLAN (5.40-5.725 GHz) and HisWaNa (5.15-5.25 $\mathrm{GHz}$ ) wireless application bands.

\section{Antenna Configuration}

The geometry of the proposed antenna is shown in Figure 1. The radiating patch of the proposed antenna is shown in Figure 1(a) and the ground plane of the proposed monopole antenna is shown in Figure 1(b). The filled grey color part in Figures 1(a) and 1(b) indicates that conducting material is present in these parts. The proposed antenna is printed on an inexpensive FR-4 substrate of thickness $1.585 \mathrm{~mm}$ and relative permittivity of 4.4. The method of moment based electromagnetic simulator IE3D [13] is applied for parametric investigation in the proposed antenna design. The top side of the substrate consists of a rectangular radiating patch of size $16 \times 12 \mathrm{~mm}^{2}$ and a $50 \mathrm{ohm}$ microstrip feed-line of width $3 \mathrm{~mm}$ and length $9 \mathrm{~mm}$. The bottom side of the substrate consists of a ground plane of size $6 \mathrm{~mm} \times 18 \mathrm{~mm}$. A small $\mathrm{U}$ shaped slot having an area of only $3 \times 4$ $\mathrm{mm}^{2}$ is etched from the ground plane to improve the impedance bandwidth of the proposed monopole antenna for dual band operation. A $50 \mathrm{ohm}$ standard miniature adapter (SMA) is used to feed the microstrip line for RF signal input. The overall dimension of the proposed antenna is only $25 \times 18 \times 1.5875 \mathrm{~mm}^{2}$. The optimal dimensions of the proposed antenna are $W_{\text {sub }}=25 \mathrm{~mm}, L_{\text {sub }}=18 \mathrm{~mm}, W_{p}=16 \mathrm{~mm}, L_{p}=12 \mathrm{~mm}$, $W_{f}=3 \mathrm{~mm}, L_{f}=9 \mathrm{~mm}, W_{g}=6 \mathrm{~mm}, L_{g}=18 \mathrm{~mm}, W_{3}=7 \mathrm{~mm}, W_{1}=3 \mathrm{~mm}, \mathrm{~L}_{1}=4 \mathrm{~mm}$, $\mathrm{W}_{2}=2 \mathrm{~mm}, \mathrm{~L}_{2}=3 \mathrm{~mm}, \mathrm{~W}=3.5 \mathrm{~mm}$. 

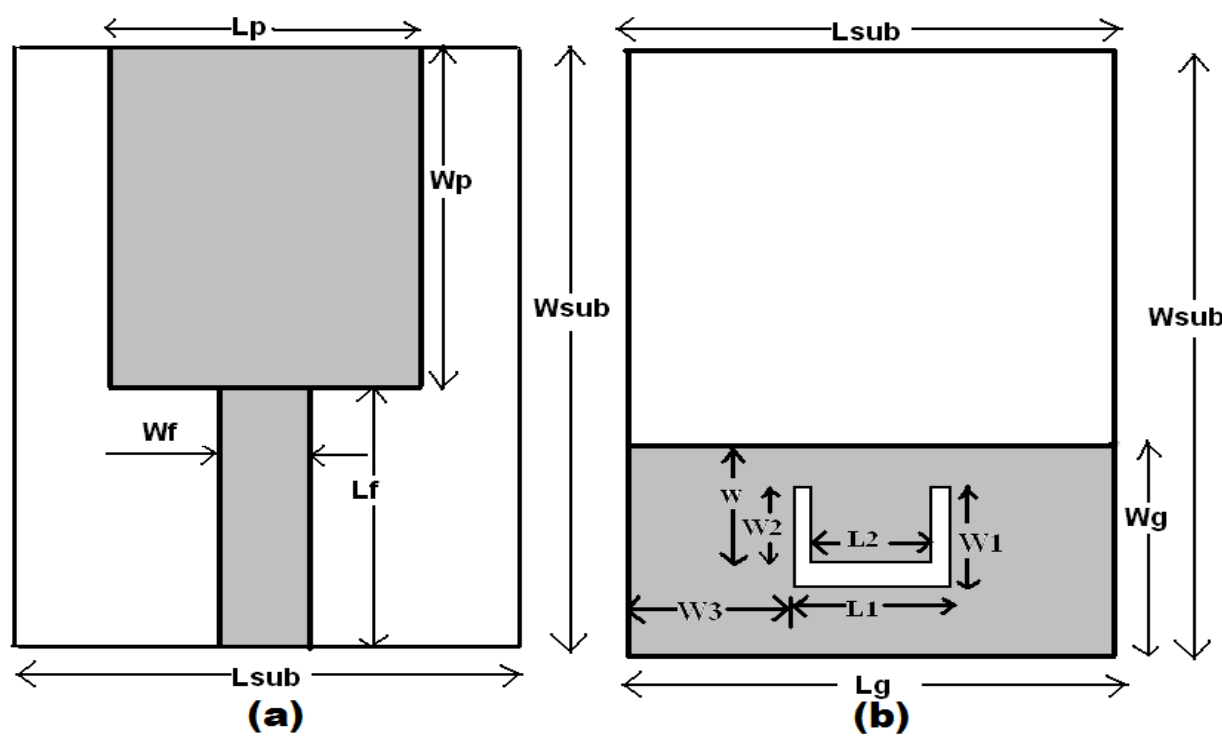

Figure 1. Geometry of the Proposed Antenna (a) Patch (b) Ground plane

\section{Analysis and Working of the Proposed Antenna}

The working principle of the proposed antenna can be explained with the help of surface current distributions. The surface current distribution of the antenna with simple ground plane (without U-shaped slot) is shown in Figure 2. It is clearly noticed from Figure 2 that the current density is much less at the surface of the ground plane of the antenna. So, the current density at the surface of the ground plane can be increased by introducing some additional slots. The slot is taken of $U$ shaped because of its dual resonance characteristics. Through a number of simulations using IE3D, all the parameters such as length and width of the ground plane, position of the $U$ shaped slot in the ground plane and dimensions of the $\mathrm{U}$ shaped slot were first optimized that affect the distribution of surface current. The surface current distribution of the proposed antenna with $\mathrm{U}$ shaped defect in the ground plane is shown in Figure 3. It is clearly observed from the Figures that the surface current distributions shown in Figure 2 and Figure 3 are not identical. The surface currents originate around the $\mathrm{U}$ shaped slot and the current density is much stronger around the outside arms of the $U$ shaped slot [see Figure 3]. The surface current distribution of the proposed antenna changes due to presence of the $U$ shaped slot that changes the resonance behavior of the antenna. This is due to the fact that the electric and magnetic field distribution changes due to the lengthening of the surface current around the arms of the U shaped slot. Surface current mainly concentrates at the edges of the $U$ shaped slot and thereby increases the current path. Due to lengthening of surface current around the slot, the resonant frequency decreases. Depending on the shape and dimensions of the $U$ shaped defect in the ground plane, the shielded current distribution in the ground plane is disturbed which results in a controlled excitation and propagation of the electromagnetic waves through the substrate layer. The currents along the edges of the $\mathrm{U}$ shaped slot introduce additional resonance, which in conjunction with the resonance of the main patch produce an overall broadband frequency response characteristic. For the proposed antenna, the band-gap of the defected ground plane and the resonant frequency of the patch antenna overlaps, therefore inhibiting the surface wave propagation. Due to modifications in the ground plane, a parasitic field or fringing is created and this creation of fringing field increases the coupling between the conducting patch and ground plane. This increased coupling enhances the operating bandwidth of the antenna. The bandwidth enhancement process may be also realized by obtaining more than one resonant frequency 
that radiates under $10 \mathrm{~dB}$ level and the resonance envelopes provide the desired bandwidth.
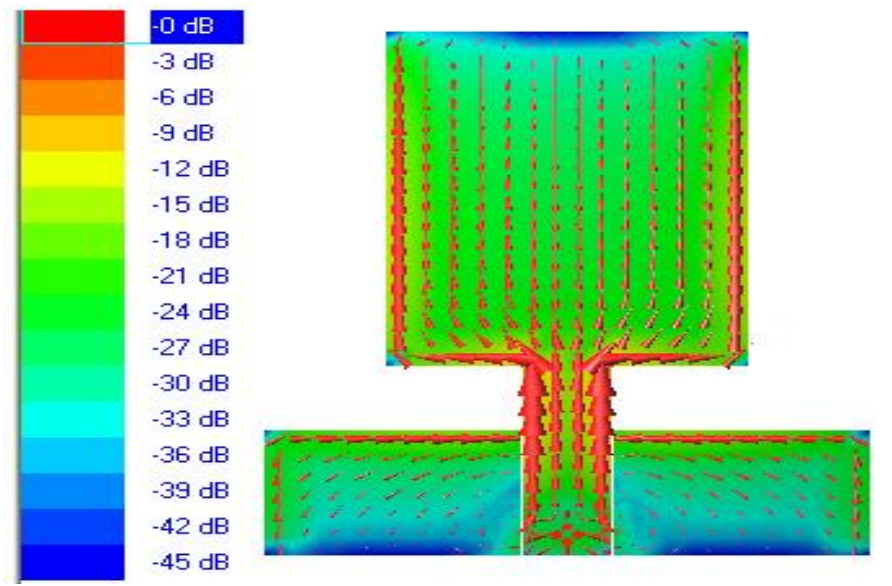

\section{Figure 2. Surface Current Distribution of the Antenna without U Shaped Slot in the Ground Plane}

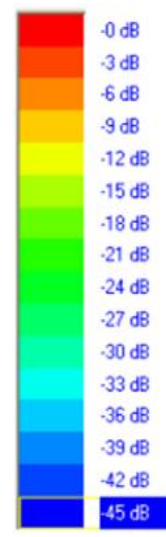

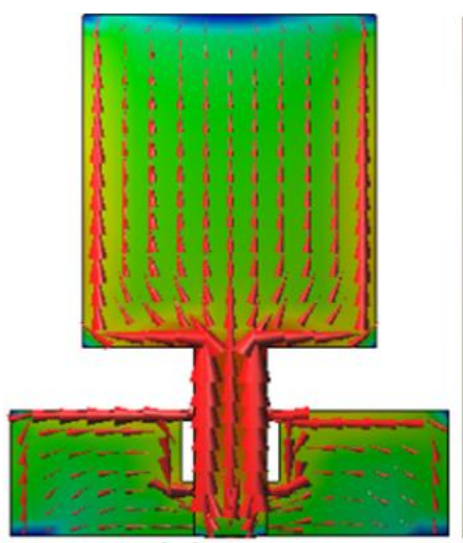

(a)

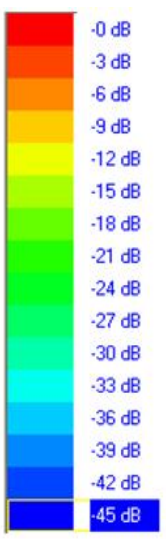

$2 \mathrm{~dB}$

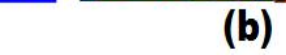

Figure 3. Surface Current Distribution of the Proposed Antenna at (a) 3.3 $\mathrm{GHz}$ (b) $5.56 \mathrm{GHz}$

\section{Theoretical Considerations}

The equivalent circuit of the $\mathrm{U}$ shaped slot loaded defected ground plane is presented and discussed in this section. The parameters of the equivalent circuit are represented in terms of optimized dimensions of the proposed antenna. Due to the resonant behavior of the defected ground structure (DGS), it may be compared with the LC parallel resonator that means the equivalent circuit of DGS consists of an inductance and capacitance in parallel. For the proposed antenna structure, the ground plane of the antenna is defected with $U$ shaped slot. The structure of the $U$ shaped slot loaded ground plane is shown in Figure 4. The L-C equivalent circuit of the ground plane (without $U$ shaped slot) is shown in Figure 5. The values of $L_{1}$ and $C_{1}$ in Figure 4 can be defined as [14].

$$
\begin{gathered}
\mathrm{C}_{1}=\frac{\varepsilon_{\mathrm{e}} \varepsilon_{0} \mathrm{LgW}_{\mathrm{g}}}{2 \mathrm{~h}} \cos ^{-2}\left(\pi \mathrm{y}_{0} / \mathrm{L}\right) \\
\mathrm{L}_{1}=\frac{1}{\omega^{2} \mathrm{C}_{1}}
\end{gathered}
$$


In which, $\mathrm{L}_{\mathrm{g}}$ and $\mathrm{W}_{\mathrm{g}}$ are the length and width of the rectangular ground plane, $\mathrm{y}_{0}$ is the location of the probe feed at the edge of the microstrip line, $h$ is the thickness of the substrate material and $\varepsilon_{e}=$ effective permittivity of the medium which is given by [14].

$$
\varepsilon_{\mathrm{e}}=\frac{\varepsilon_{\mathrm{r}}+1}{2}+\frac{\varepsilon_{\mathrm{r}}-1}{2}\left[1+10 \frac{\mathrm{h}}{\mathrm{W}_{\mathrm{g}}}\right]^{-1 / 2}
$$

In which, $\varepsilon_{r}$ is the relative permittivity of the substrate.

The equivalent circuit of the ground plane loaded with $U$ shaped slot can be realized by considering two sections in the ground plane. First section (upper) is an E shaped slot and second (lower one) as microstrip bend line. Section 1 is analyzed as a ground plane in which two parallel (vertical) slots are incorporated. This perturbation in the ground plane changes the current length which is accounted for by an additional series inductance $\Delta \mathrm{L}$ and a series capacitance $\Delta \mathrm{C}$. The equivalent circuit of the first section is shown in Figure 6 , in which the additional series inductance is given as [15]

$$
\Delta \mathrm{L}=\frac{\mathrm{Z}_{1}+\mathrm{Z}_{2}}{16 \pi \mathrm{f} \cos ^{-2}\left(\frac{\pi \mathrm{y}_{0}}{\mathrm{~W}}\right)} \tan \left(\frac{\pi \mathrm{fW}}{\mathrm{C}}\right)
$$

The values of $Z_{1}$ and $Z_{2}$ are given as [15]

$$
\begin{aligned}
\mathrm{Z}_{1} & =\frac{120 \pi}{\frac{\mathrm{L}_{1}}{\mathrm{~h}}+1.393+0.667 \ln \left(\frac{\mathrm{L}_{1}}{\mathrm{~h}}+1.444\right)} \\
\mathrm{Z}_{2} & =\frac{120 \pi}{\frac{\left(\mathrm{L}_{1}-2 \mathrm{~d}\right)}{\mathrm{h}}+1.393+0.667 \ln \left(\frac{\mathrm{L}_{1}-2 \mathrm{~d}}{\mathrm{~h}}+1.444\right)}
\end{aligned}
$$

The parameters $\mathrm{Z}_{1}$ and $\mathrm{Z}_{2}$ are the characteristic impedance of the vertical slots; $\mathrm{W}_{2}$ is the depth of the vertical slot, $d$ is the width of the vertical slots, $h$ is the thickness of the substrate, $L_{2}$ is the length of the inner arm of $U$ shaped slot and $L_{1}$ is the length of the outer arm of $\mathrm{U}$ shaped slot.

The capacitance $\Delta \mathrm{C}$ is calculated as gap capacitance given by [16].

$$
\Delta \mathrm{C}=2 \mathrm{~W}_{2} \frac{\varepsilon_{0}}{\pi}\left[\ln \left(2 \frac{1+\sqrt{\mathrm{k} /}}{1+\sqrt{\mathrm{k}^{\prime}}}\right)+\ln \operatorname{coth}\left(\frac{\pi \mathrm{d}}{4 \mathrm{~h}}\right)+0.013 \mathrm{C}_{\mathrm{f}} \frac{\mathrm{h}}{\mathrm{d}}\right] \times \cos ^{-2}\left(\frac{\pi \mathrm{y}_{0}}{\mathrm{~W}}\right)
$$

In which, $\mathrm{C}_{\mathrm{f}}$ is the fringe capacitance.

The parameter $k^{/}$is given as [17]

$$
\begin{aligned}
& k^{\prime}=\sqrt{1-k^{2}} \\
& \text { Where, } k^{2}=\frac{\left(\frac{2 L_{1}}{d}-1\right)}{\left(1+\frac{L_{1}}{d}\right)\left(\frac{L_{1}-d}{d}\right)}
\end{aligned}
$$

So, the equivalent circuit of the first section is modified as Figure 7, in which

$$
\begin{aligned}
& \text { Total modified inductance, } \mathrm{L}_{2}=\mathrm{L}_{1}+\Delta \mathrm{L} \\
& \text { Total modified capacitance, } \mathrm{C}_{2}=\frac{\mathrm{C}_{1} \Delta \mathrm{C}}{\mathrm{C}_{1}+\Delta \mathrm{C}}
\end{aligned}
$$

The second section is considered as two microstrip bend line and the equivalent impedance of this shape is given as [18].

$$
\mathrm{Z}_{0}=\mathrm{j} \omega \mathrm{L}_{0}+\frac{1}{\frac{1}{\mathrm{j} \omega \mathrm{L}_{0}}+\mathrm{j} \omega \mathrm{C}_{0}}
$$

Where, $\frac{\mathrm{C}_{0}}{\mathrm{~W}_{3}}=\left(9.5 \varepsilon_{\mathrm{r}}+1.25\right) \frac{\mathrm{W}_{3}}{\mathrm{~h}}+5.2 \varepsilon_{\mathrm{r}}+7.0 \mathrm{pF} / \mathrm{m}$

$$
\frac{2 \mathrm{~L}_{0}}{\mathrm{~h}}=100\left(4 \sqrt{\frac{\mathrm{W}_{3}}{\mathrm{~h}}-4.21}\right) \mathrm{nH} / \mathrm{m}
$$


The parameter $\mathrm{C}_{0}$ is the capacitance of microstrip bend line; $\mathrm{L}_{0}$ is the inductance of microstrip bend line and $\mathrm{W}_{3}$ is the separation between the edges of the ground plane and microstrip bend line.

Combining the above two sections, the equivalent circuit of the $U$ shaped slot loaded ground plane is shown in Figure 8.

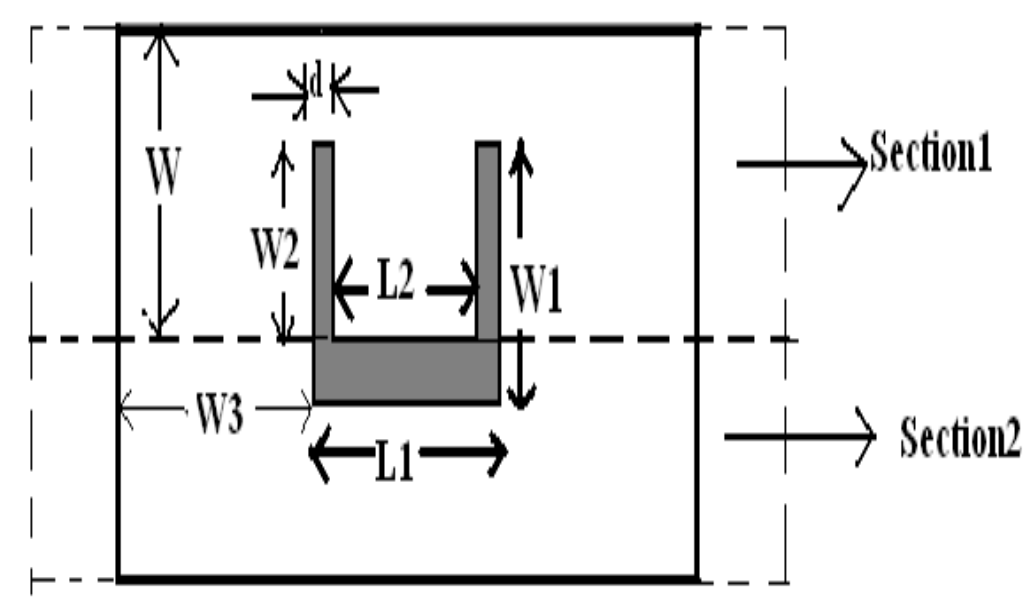

Figure 4. Structure of the U Slot Loaded Ground Plane

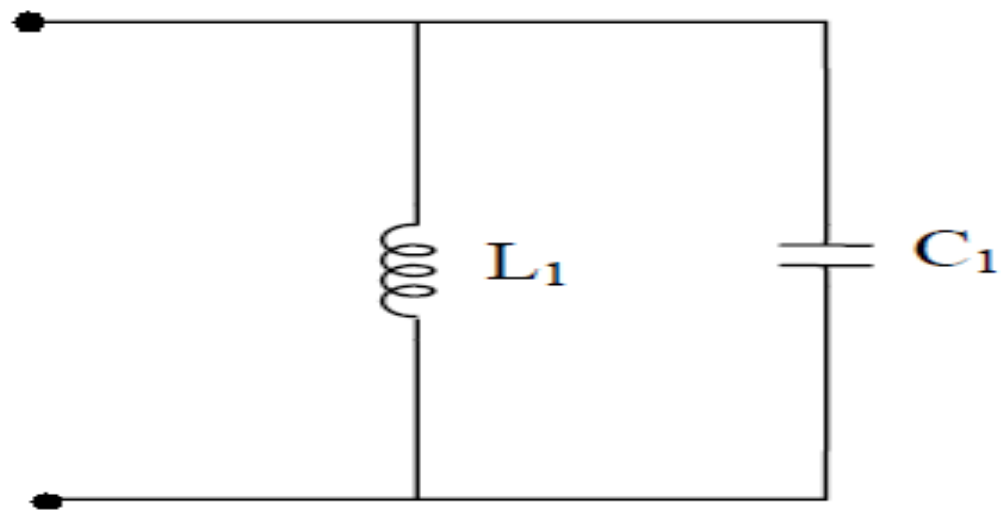

Figure 5. LC Equivalent of the Ground Plane

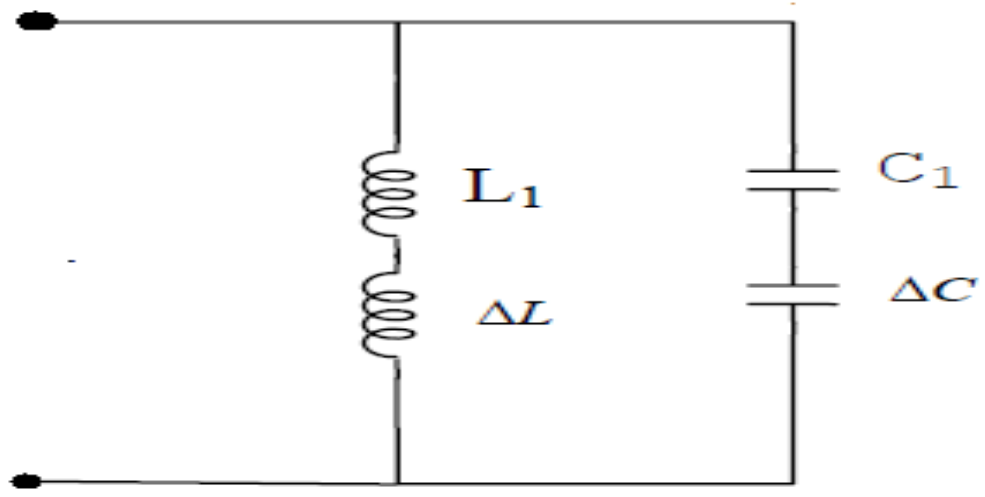

Figure 6. Equivalent Circuit of Section1 


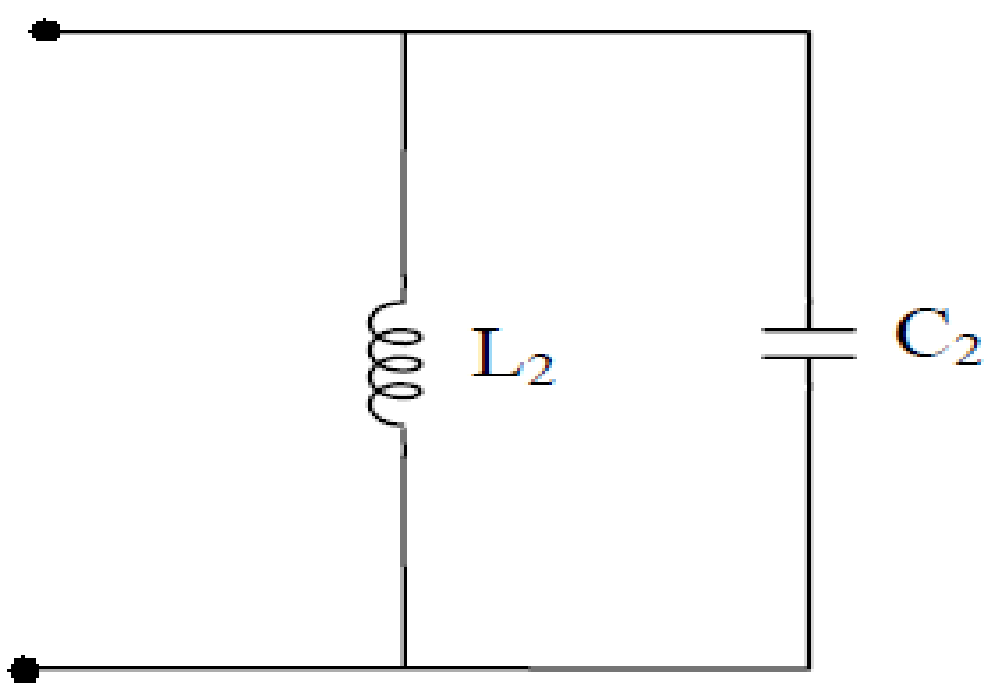

Figure 7. Modified Circuit of Section1

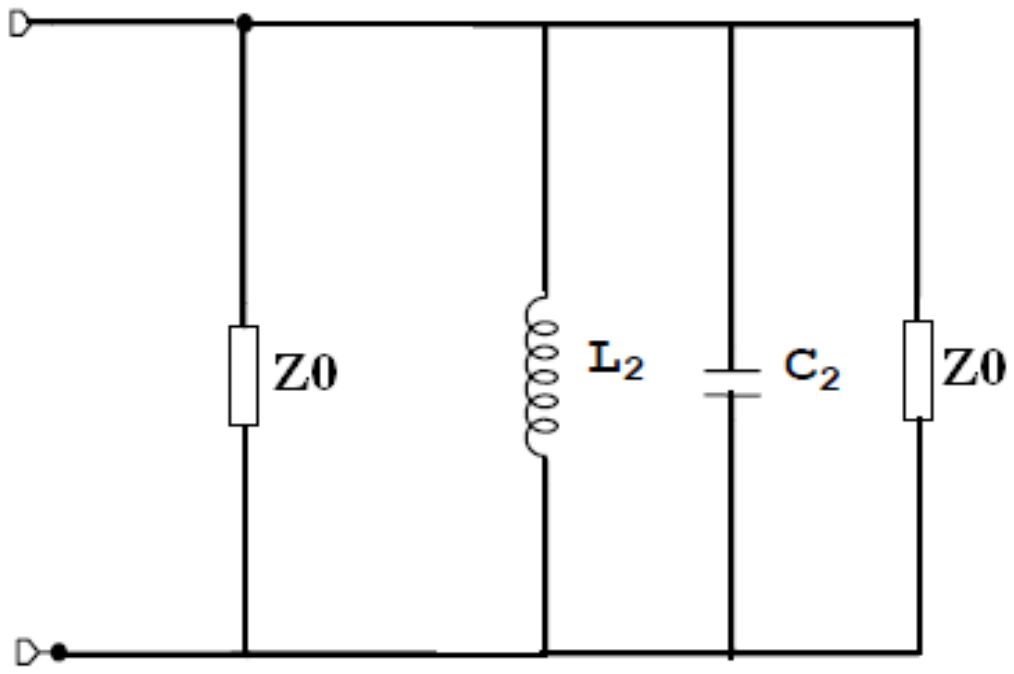

Figure 8. Equivalent Circuit of the U Slot Loaded Defected Ground Plane

\section{Parametric Study of the Proposed Antenna}

The parametric study of the proposed antenna has been carried out using Method-ofMoment-based IE3D software to study the effects of various parameters on the performance of the antenna. The structural effect of the ground plane on the performance of the antenna is investigated by mounting the proposed antenna structure on either of two different types of ground planes. The first is a conventional perfect electrical conductor (PEC) ground plane i.e., without defection (U shaped slot) in the ground plane and the other is a defected ground plane. The defected ground plane consists of an etched $U$ shaped slot having an area of only $3 \times 4 \mathrm{~mm}^{2}$. The variation of operating bandwidth by the effect of small $U$ shaped slot embedded in the ground is depicted in Figure 9. The $10 \mathrm{~dB}$ return loss bandwidth of the proposed antenna without introducing $U$ shaped slot in the ground plane ranges from 3.0-3.65 GHz for the lower band and 5.95-6.15 GHz for the upper band. But the addition of small $U$ shaped defect in the ground plane improves the bandwidth of the antenna significantly. The bandwidth achieved for the lower band ranges from $2.98-3.82 \mathrm{GHz}$ and for the upper band 4.54-6.48 GHz. So, it is observed that there are two major advantages associated with the introduction of $U$ shaped slot in the ground 
plane of the proposed antenna. First, the return loss and thereby the impedance matching of the antenna with $U$ shaped defect in ground plane is better than the corresponding return loss of the antenna with conventional PEC ground plane at upper frequency band. Second, the antenna shows much improved bandwidth at both of the operating bands. The effects of the effective structural parameters of the $U$ shaped slot are investigated by slightly changing only one structural parameter from the reference design at the time of simulation while all other parameters remain fixed. The results of the parametric study are shown in Figures 10-13. The effects of the parameters W2 and L2 of $U$ shaped slot are depicted in Figures 10-11. It is clearly viewed from Figures 10-11 that the parameters W2 and L2 do not have major influence on the resonant characteristics of the proposed antenna. The effects of the $\mathrm{W} 1$ and $\mathrm{L} 1$ parameters of $\mathrm{U}$ shaped slot are depicted in Figures 12-13. It can be observed from Figures 12-13 that the resonant characteristics of the antenna especially at the upper band are greatly influenced by the variations of the parameters W1 and L1. The results of Figures 10-13 are summarized in Table 1. It can be concluded from Table 1 that further changes in the structural parameters of the $U$ shaped slot than the proposed dimensions will decrease the bandwidth of the proposed antenna at both of the frequency bands.

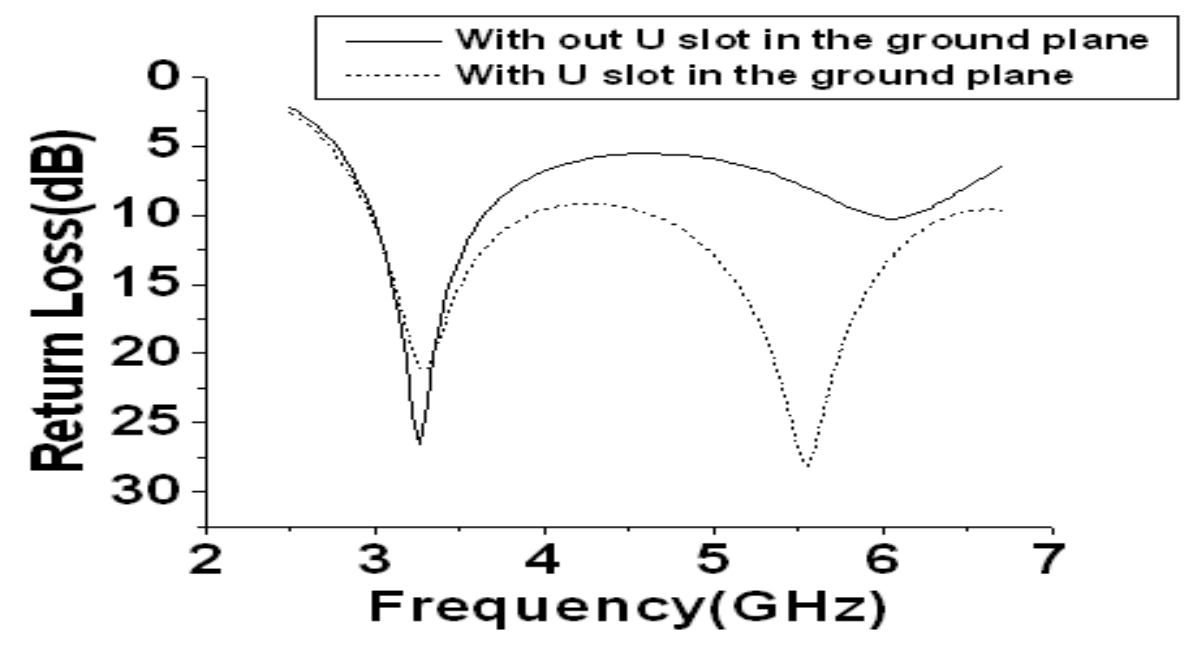

Figure 9. Simulated Return Loss with and without Presence of U Shaped Slot on the Ground Plane

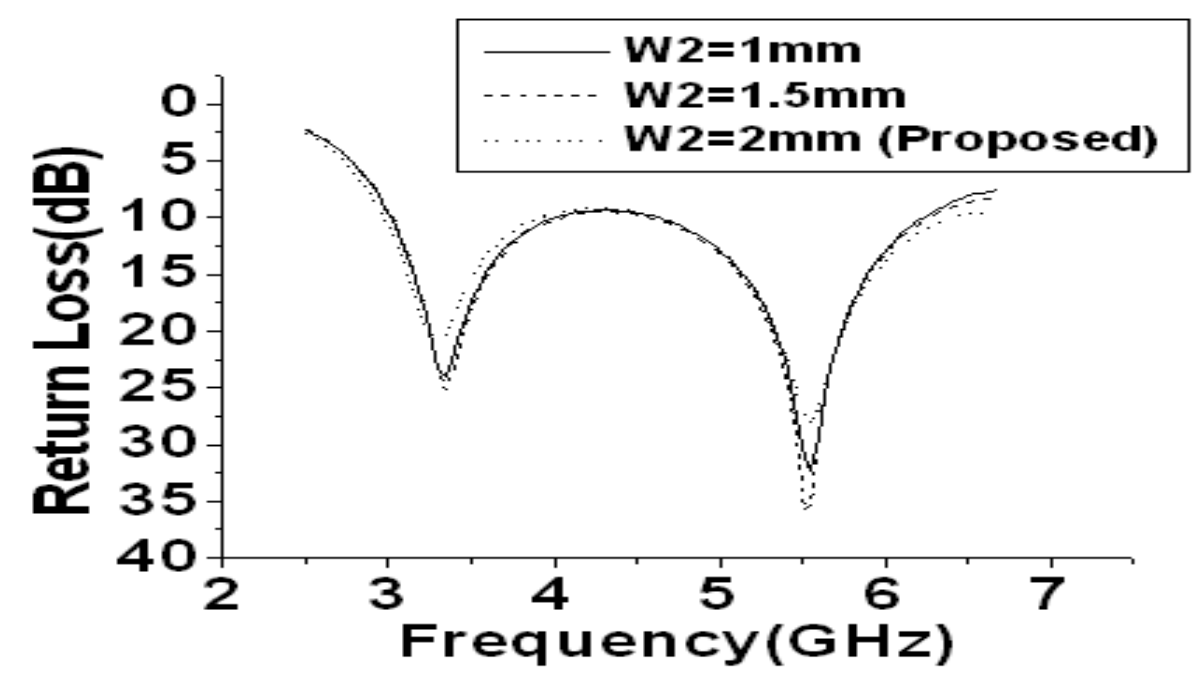

Figure 10. Variations of Return Loss as a Function of Parameter W2 of $U$ Shaped Slot 


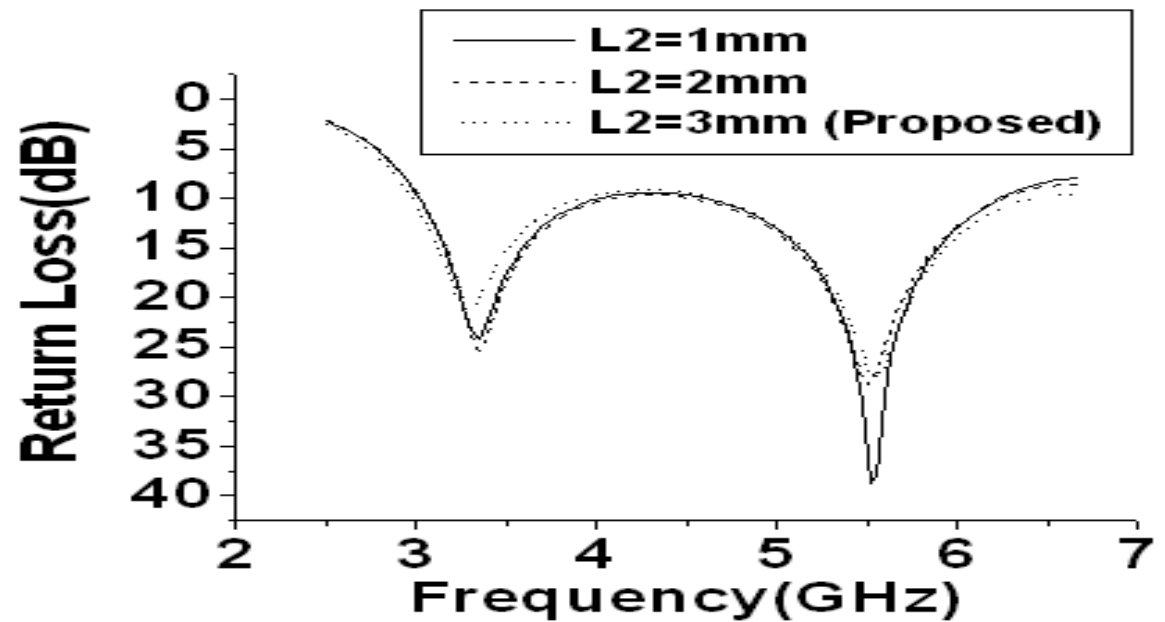

Figure 11. Variations of Return Loss as a Function of Parameter L2 of $U$ Shaped Slot

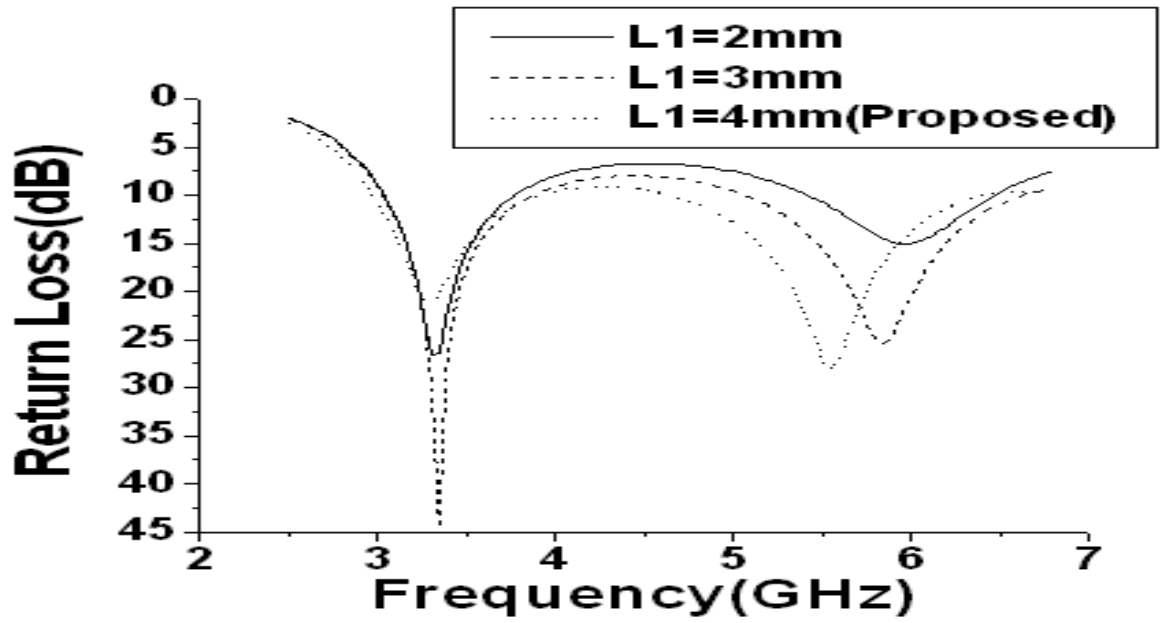

Figure 12. Variations of Return loss as a Function of Parameter L1 of U Shaped Slot

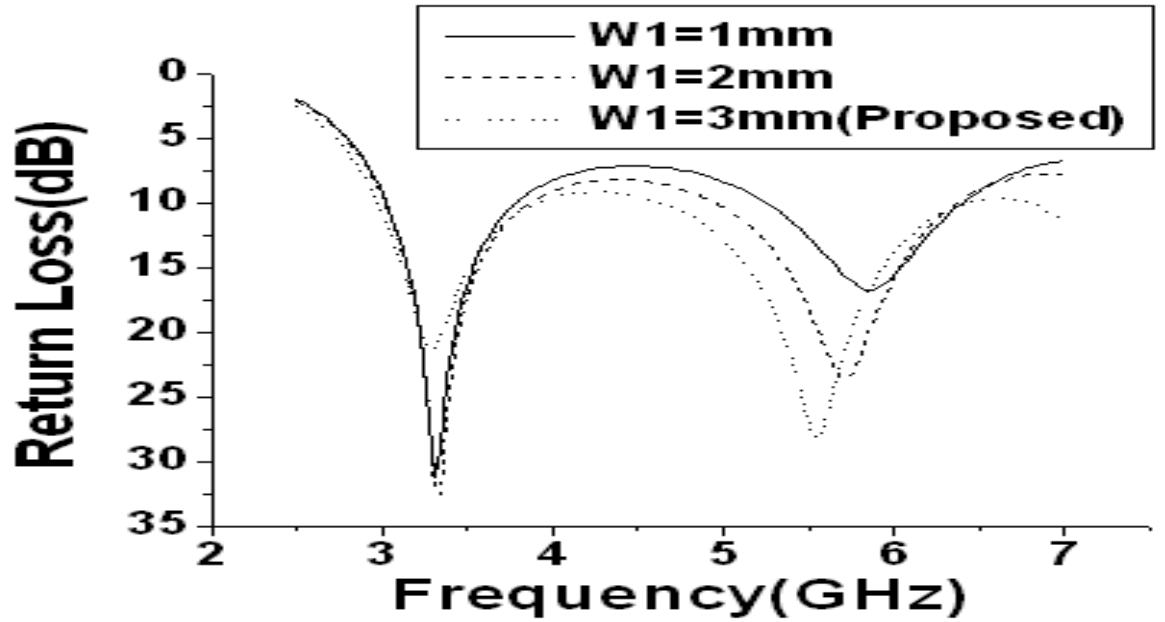

Figure 13. Variations of Return loss as a Function of Parameter W1 of U Shaped Slot 
Table 1. Simulated Results of the Proposed Antenna by Varying the Parameters of U-Shaped Slot of the Ground Plane

\begin{tabular}{|c|c|c|c|}
\hline $\begin{array}{c}\text { U-Shaped Slot } \\
\text { Parameters } \\
(\mathbf{m m})\end{array}$ & $\begin{array}{c}\text { Resonant } \\
\text { Frequency } \\
(\mathbf{G H z})\end{array}$ & $\begin{array}{c}\text { Return Loss } \\
\mathbf{( d B})\end{array}$ & $\begin{array}{c}\text { 10 dB Bandwidth } \\
(\mathbf{G H z})\end{array}$ \\
\hline $\mathrm{W} 2=1$ & $3.34,5.55$ & 24,32 & $(3.0-3.9),(4.64-6.22)$ \\
\hline $\mathrm{W} 2=1.5$ & $3.34,5.52$ & $25,35.7$ & $(3.0-3.9),(4.59-6.25)$ \\
\hline $\mathrm{W} 2=2$ & $3.34,5.51$ & 22,28 & $(2.98-3.82),(4.54-6.48)$ \\
\hline $\mathrm{L} 2=1$ & $3.34,5.51$ & 24,38 & $(3.0-3.9),(4.61-6.23)$ \\
\hline $\mathrm{L} 2=2$ & $3.34,5.51$ & 25,28 & $(3.0-3.95),(4.53-6.24)$ \\
\hline $\mathrm{L} 2=3$ & $3.34,5.51$ & 22,28 & $(2.98-3.82),(4.54-6.48)$ \\
\hline $\mathrm{L} 1=2$ & $3.30,5.92$ & $26.6,15$ & $(3.03-3.76),(5.4-6.47)$ \\
\hline $\mathrm{L} 1=3$ & $3.34,5.80$ & 44,25 & $(3.03-3.87),(5.0-6.53)$ \\
\hline $\mathrm{L} 1=4$ & $3.34,5.51$ & 22,28 & $(2.98-3.82),(4.54-6.48)$ \\
\hline $\mathrm{W} 1=1$ & $3.30,5.71$ & 31,16 & $(3.03-3.77),(5.25-6.38)$ \\
\hline $\mathrm{W} 1=2$ & $3.30,5.67$ & 32,24 & $(3.01-3.86),(4.95-6.36)$ \\
\hline $\mathrm{W} 1=3$ & $3.34,5.51$ & 22,28 & $(2.98-3.82),(4.54-6.48)$ \\
\hline
\end{tabular}

\section{Results and Discussion}

A prototype of the proposed antenna with optimal geometrical parameters was constructed and measured. The return loss of the fabricated antenna has been measured using agilent vector network analyzer E5071B. Figure 14 shows the measured and simulated frequency responses of return loss for the proposed design for the purpose of comparison. The Simulated result shows that there exists dual band of wide operating impedance-bandwidth. A $10 \mathrm{~dB}$ return loss bandwidth of $840 \mathrm{MHz}$ is obtained from 2.98 $\mathrm{GHz}$ to $3.82 \mathrm{GHz}$, which is $24.70 \%$ bandwidth around the centre frequency of $3.4 \mathrm{GHz}$. Another wide operating bandwidth of $1940 \mathrm{MHz}$ is obtained from $4.54 \mathrm{GHz}$ to $6.48 \mathrm{GHz}$, which is $35.20 \%$ bandwidth around the centre frequency of $5.51 \mathrm{GHz}$. The measured result shows $10 \mathrm{~dB}$ return loss bandwidth of about $680 \mathrm{MHz}$ from $2.92 \mathrm{GHz}$ to $3.6 \mathrm{GHz}$, which is $20.85 \%$ around the centre frequency of $3.26 \mathrm{GHz}$ at the lower band. Another wide operating $10 \mathrm{~dB}$ return loss bandwidth of about $2300 \mathrm{MHz}(4.12-6.42 \mathrm{GHz})$, which is $43.64 \%$ around the centre frequency of $5.27 \mathrm{GHz}$ is obtained at the upper band. The agreements between the simulated and measured results are reasonably good. The overall discrepancy of $200 \mathrm{MHz}$ bandwidth between the simulated and measured results may be due to improper soldering of SMA connector at microstrip feed line or tolerance in fabrication process. The simulated and measured results of the proposed antenna are summarized in Table 2. The simulated and measured gain of the proposed antenna is shown in Figure 15. The measured peak gain of about $3 \mathrm{dBi}$ is obtained at $5 \mathrm{GHz}$. The range of the measured gain of the proposed antenna is $1-3 \mathrm{dBi}$ over the working frequency bands. The gain of the proposed antenna is measured using a standard gain antenna procedure. The standard gain horn antenna is used as a reference antenna. The difference between simulated and measured gain may be due to variations of simulated and measured return loss, improper soldering of SMA connector or tolerance in fabrication and measurement process. The simulated and measured gain may also differ at the respective frequencies because the gain of the reference horn antenna is not identical for all the frequencies. The $\mathrm{E}$ and $\mathrm{H}$ plane radiation patterns of the proposed antenna are shown in Figures 16-17. The results are normalized to the maximum radiation level. The proposed monopole antenna features stable radiation patterns over the desired operating bands. The radiation patterns of the proposed antenna are nearly identical at both of the 
working frequency bands and this may be due to almost similar type of current distributions at both of the desired frequency bands.

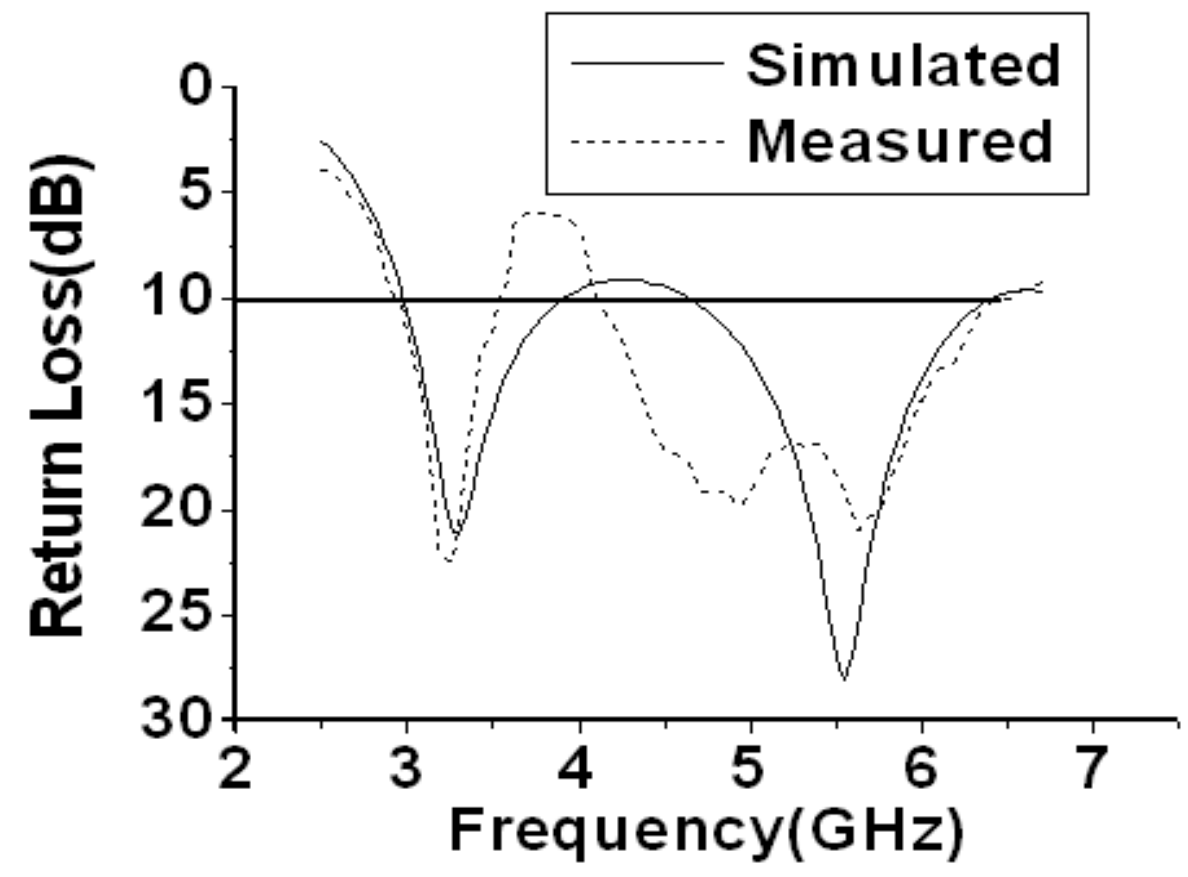

Figure 14. Simulated and Measured Return Loss of the Proposed Antenna

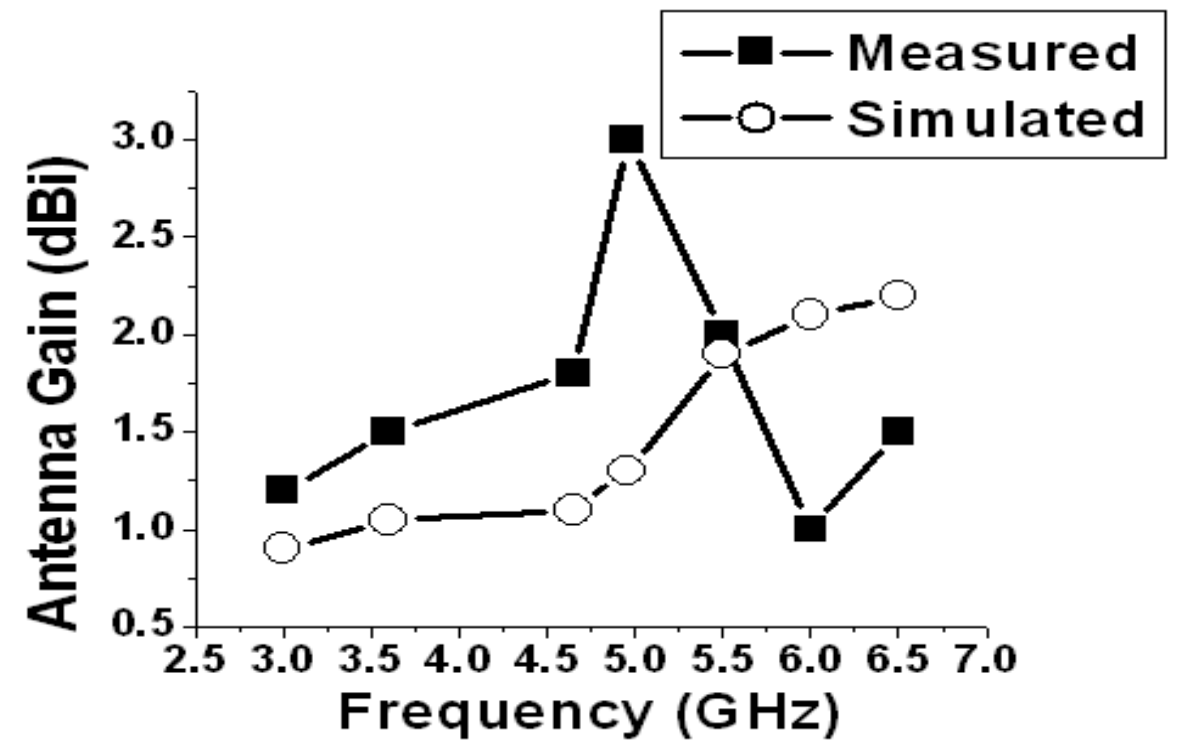

Figure 15. Simulated and Measured Gain of the Proposed Antenna 

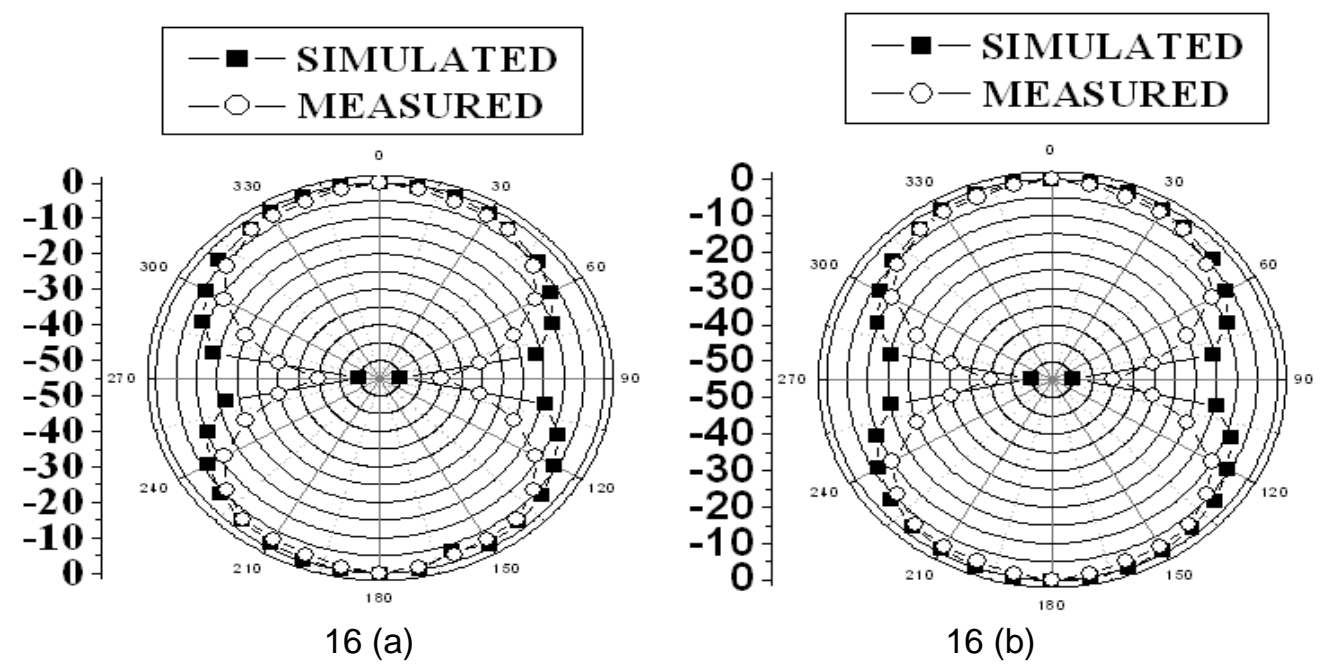

Figure16. Simulated and Measured Normalized E Plane Radiation Pattern of the Proposed Antenna at (a) $3.3 \mathrm{GHz}$ (b) $5.56 \mathrm{GHz}$

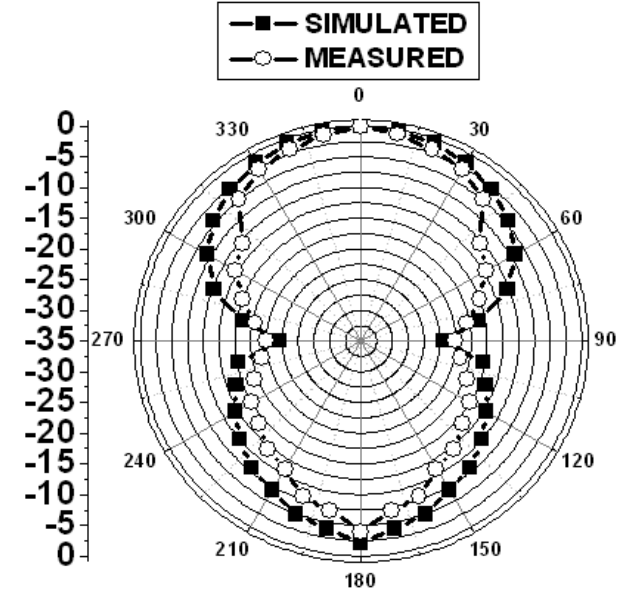

17 (a)

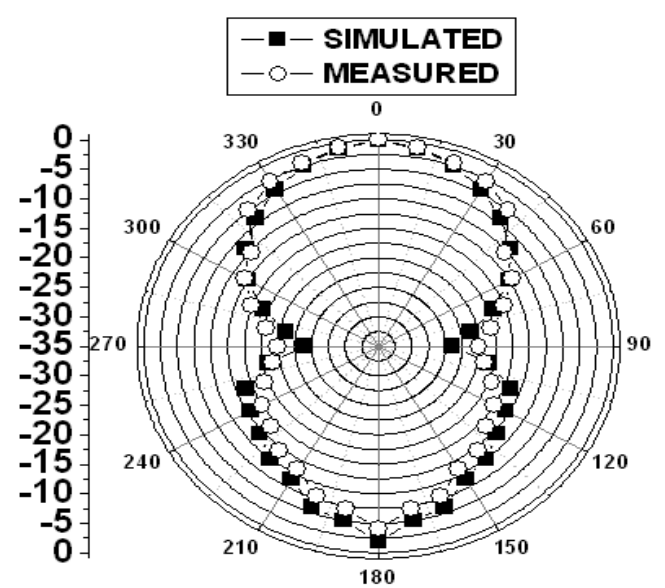

17 (b)

Figure 17. Simulated and Measured Normalized H Plane Radiation Pattern of the Proposed Antenna at (a) $3.3 \mathrm{GHz}$ (b) $5.56 \mathrm{GHz}$

Table 2. Simulated and Measured Results of the Proposed Antenna

\begin{tabular}{|c|c|c|c|c|}
\hline \multicolumn{2}{|c|}{$\begin{array}{c}\text { Proposed } \\
\text { Antenna }\end{array}$} & $\begin{array}{c}\text { Centre } \\
\text { Frequency } \\
\text { (GHz) }\end{array}$ & $\begin{array}{c}\text { 10 dB Return } \\
\text { loss bandwidth } \\
\text { (GHz) }\end{array}$ & $\begin{array}{c}\text { Bandwidth } \\
(\%)\end{array}$ \\
\hline \multirow{2}{*}{ Simulated } & Lower band & 3.40 & $(2.98-3.82)$ & 24.70 \\
\cline { 2 - 5 } & Upper band & 5.51 & $(4.54-6.48)$ & 35.20 \\
\hline \multirow{2}{*}{ Measured } & Lower band & 3.26 & $(2.92-3.60)$ & 20.85 \\
\cline { 2 - 5 } & Upper band & 5.27 & $(4.12-6.42)$ & 43.64 \\
& & & & \\
\hline
\end{tabular}




\section{Performance Comparison of the Proposed Antenna with Other Reference Works}

The performance comparison of the proposed antenna with some other works $[1,2,3$, $4,5,6,7$, and 8] is shown in Table 3. It is clear from the table that the proposed antenna not only has smaller size but also offers better impedance bandwidth at dual frequency bands to simultaneously cover the bandwidth requirement of a number of modern wireless communication application bands such as WiMAX $(3.30-3.60 \mathrm{GHz}, 5.25-5.85 \mathrm{GHz})$, WLAN (5.15-5.35 GHz, 5.725-5.825 GHz), HiPERLAN $(5.40-5.725 \mathrm{GHz})$ and HisWaNa (5.15-5.25 GHz) wireless application bands.

Table 3. Performance Comparison with other Antennas

\begin{tabular}{|c|c|c|}
\hline Works & $\begin{array}{c}\text { Antenna Dimensions } \\
(\mathbf{L} \times \mathbf{W}) \mathbf{~ m m}^{\mathbf{2}}\end{array}$ & $\begin{array}{c}\text { Operating Bands } \\
(\mathbf{G H z})\end{array}$ \\
\hline Ref [1] & $20 \times 38.5$ & $2.40-2.72$ and $4.87-6.05$ \\
\hline Ref [2] & $30 \times 50$ & $2.386-2.51$ and $4.878-6.0$ \\
\hline Ref [3] & $42.06 \times 51.55$ & $2.28-2.62$ and 4.52-6.0 \\
\hline Ref [4] & $60 \times 100$ & $0.881-1.280$ and $1.7-2.568$ \\
\hline Ref [5] & $35 \times 50$ & $2.05-2.86$ and 5.55-6.14 \\
\hline Ref [6] & $20 \times 28$ & $2.36-2.58$ and 4.53-6.38 \\
\hline Ref [7] & $38 \times 38$ & $2.40-2.48$ and 5.15-5.825 \\
\hline Ref [8] & $20 \times 25$ & $2.39-2.52$ and 4.97-6.07 \\
\hline This Paper & $18 \times 25$ & $2.92-3.60$ and 4.12-6.42 \\
\hline
\end{tabular}

\section{Conclusion}

A compact microstrip line fed printed monopole antenna for wireless communication applications is proposed in this paper. The proposed antenna shows dual band (2.92-3.60 $\mathrm{GHz}$ and 4.12-6.42 GHz) operation with broad impedance bandwidth by employing a $\mathrm{U}$ shaped slot loaded partial ground plane. The Measured result shows reasonable agreement with the simulated results which validates our design concept. The proposed antenna can be considered as an attractive candidate for applications in a number of modern wireless communication systems due to its small size, simple structure, broad bandwidth and good radiation pattern characteristics. The proposed antenna covers the bandwidth requirements of 5.2/5.8 GHz WLAN, $5 \mathrm{GHz}$ HiPERLAN, $5.2 \mathrm{GHz}$ HisWaNa and $3.5 / 5.5 \mathrm{GHz}$ WiMAX bands.

\section{References}

[1] N. Chang and J. H. Jiang, "Meandered T-shaped monopole antenna", IEEE Trans.Antennas Propag., vol. 57, (2009), pp. 3976-3978.

[2] C.-Y. Huang and E.-Z. Yu, "A slot monopole antenna for dual band WLAN applications", IEEE Antennas wireless Propagation Letters, vol. 10, (2011), pp. 500-502.

[3] C.- M. Wu, "Dual-band CPW-fed cross-slot monopole antenna for WLAN operation", IET Microwave Antennas Propag., vol. 1, (2007), pp. 542-546.

[4] W.-S. Chena and B.-Y. Leeb, "Novel printed monopole antenna for PDA phone and WLAN applications", Journal of Electromagnetic Waves and Applications, vol. 23, (2009), pp. 2073-2088.

[5] J. R. Panda and R. S. Kshetrimayum, "A Printed $2.4 \mathrm{GHz} / 5.8 \mathrm{GHz}$ dual band monopole antenna with a protruding stub in the ground plane for WLAN and RFID applications", Progress in Electromagnetic Research, vol. 117, (2011), pp. 425-434.

[6] W. Hu, Y. Z. Yin, X. Yang and X. S. Ren, "Compact printed antenna with h-shaped stub for dual-band operation", Electronic Letters, vol. 46, (2010), pp. 1644-1645.

[7] W. Hu, Y.-Z. Yin, X. Yang, K. Song, Z.-Y. Liu and L.-H. Wen, "A wide open U slot antenna with a pair of symmetrical L-strips for WLAN applications”, PIER Letters, vol. 16, (2010), pp. 141-149. 
[8] W.-S. Chen, B.-Y. Lee and P.-Y. Chang, "A compact and small printed monopole antenna for WLAN applications", Microwave and Opt Technol. Lett., vol. 53, (2011), pp. 1518-1522.

[9] Y. Song, Y. C. Jiao, X. M. Wang, Z. B. Weng and F. S. Zhang, "Compact coplanar slot antenna fed by asymmetric coplanar strip for 2.4/5 GHz WLAN operations", Microwave and Opt Technol. Lett., vol. 50, (2008), pp. 3080-3083.

[10] V. Deepu, R. K. Raj, M. Joseph, M. N. Suma and P. Mohanan, "Compact asymmetric coplanar strip fed monopole antenna for multiband applications”, IEEE Trans Antennas Propag., vol. 55, (2007), pp. 23512357.

[11] W. Hu, Y.-Z. Yin, P. Fei and X. Yang, "Compact tri-band square- slot antenna with symmetrical Lstrips for WLAN/WiMAX applications", IEEE Antennas and Wireless Propagation Letters, vol. 10, (2011), pp. 462-465.

[12] L. Xiong and P. Gao, "A compact triple-band wide-slot antenna for WLAN/WiMAX applications", Journal of Electromagnetic Waves and Applications, vol. 26, (2012), pp. 895-903.

[13] Zeland Software Inc.IE3D: MoM-Based EM Simulator.

[14] I. J. Bahl and P. Bhartia, "Microstrip antennas. Artech house", (1980).

[15] V. K. Panday and B. R. Vishvakama, "Analysis of an E-shaped patch antenna", Microwave and Opt Technol. Lett., vol. 49, (2007), pp. 4-7.

[16] I. J. Bahl, "Lumped Elements for RF and microwave Circuits", Artech house, Boston, (2003), pp. 456459.

[17] J. A. Ansari, N. P. Yadav, P. Singh and A. Mishra, "Compact half U slot loaded shorted rectangular patch antenna for broadband operation”, Progress In Electromagnetics Research M, vol. 9, (2009), pp. 215-226.

[18] J. A. Ansari, P. Singh, S. K. Dubey, R. U. Khan and B. R. Vishvakarma, "H shaped stacked patch antenna for dual band operation", Progress in Electromagnetics Research B, vol. 5, (2008), pp. 291-302.

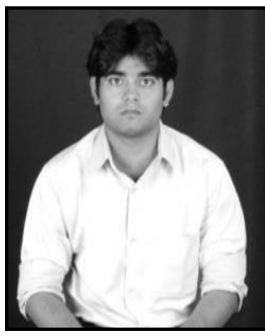

Sudipta Das is working as an Assistant Profeesor in Department of Electronics and Communication Engineering. He is presently pursuing Ph.D from University of Kalyani, INDIA. His area of research interests are Microstrip Antenna and Filter design. He has contributed 30 international research articles in various journals. The Biography of Mr. Sudipta Das is shortlisted for inclusion in the Thirty-Eighth $\left(38^{\text {th }}\right)$ Edition of the Dictionary of International Biography published by the "International Biographical Centre" of Cambridge, England. The Biography of Mr. Sudipta Das is selected in Marquis Who's who in the World 2016 (33 $3^{\text {rd }}$ Edition).

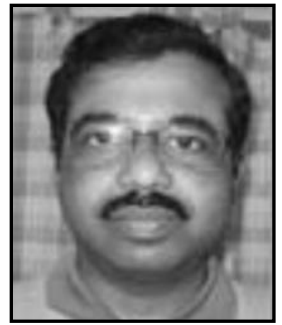

Partha Pratim Sarkar obtained his $\mathrm{Ph} . \mathrm{D}$ in engineering from Jadavpur University in the year 2002. He is presently working as Senior Scientific Officer (Professor Rank) at the Dept. of Engineering \& Technological Studies, University of Kalyani. His area of research includes, Microstrip Antenna, Microstrip Filter, Frequency Selective Surfaces, and Artificial Neural Network. He has contributed more than 250 research articles in various journals and conferences of repute. He is also a life Fellow of IETE.

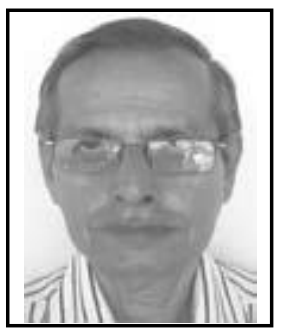

Santosh kr. Chowdhury obtained his Ph.D in engineering from Jadavpur University in the year 1971. He is a Life senior member of IEEE, Life fellow of IETE, Fellow of IE, Fellow of West Bengal Academy of Science and Technology. His area of research includes Microstrip Antenna, Microstrip Filter, and Frequency Selective surfaces. He has contributed more than 400 international research articles in various journals and conferences of repute. 